\title{
Failure of Premature Rabbits to Increase Antioxidant Enzymes During Hyperoxic Exposure: Increased Susceptibility to Pulmonary Oxygen Toxicity Compared with Term Rabbits
}

\author{
LEE FRANK AND ILENE R. S. SOSENKO
}

Departments of Medicine and Pediatrics, University of Miami School of Medicine, Miami, Florida 33101

\begin{abstract}
Although the prematurely born are known to have decreased baseline levels of protective antioxidant enzymes (Frank L, Sosenko IRS: J Pediatr 110:9 and 106, 1987), the ability to augment the baseline values during high $\mathrm{O}_{2}$ exposure is the key factor determining $\mathrm{O}_{2}$ tolerance versus $\mathrm{O}_{2}$ susceptibility. We have compared the pulmonary antioxidant enzyme responses of prematurely delivered rabbits (gestational d 29 of 32) and full-term rabbits to 48-72 h of hyperoxic exposure. We found that although full-term newborns exposed to $>90 \% \quad \mathrm{O}_{2}$ consistently showed elevated superoxide dismutase, catalase, glutathione peroxidase, and glucose-6-phosphate dehydrogenase activities, the premature animals repeatedly failed to respond to hyperoxia with increased antioxidant enzyme activity levels. Consistent with the comparative antioxidant enzyme responses were the evidences of $\mathrm{O}_{2}$ toxicity in the two age groups. The prematurely born rabbits had significantly increased lung lavage protein content, lung conjugated diene levels, and more severe light microscopic lung pathology compared with the full-term animals during equal $\mathrm{O}_{2}$ exposure time. This first reported comparison of prematurely born versus full-term animal responses to hyperoxia might help to explain the clinical observation that the very prematurely born infant is excessively prone to the development of $\mathrm{O}_{2}$-induced lung injury and the progressive development of bronchopulmonary dysplasia. (Pediatr Res 29: 292-296, 1991)
\end{abstract}

\section{Abbreviations}

SOD, superoxide dismutase

CAT, catalase

GP, glutathione peroxidase

G-6-PD, glucose-6-phosphate dehydrogenase

AOE, antioxidant enzyme

BPD, bronchopulmonary dysplasia

DSPC, disaturated phosphatidylcholine

VLBW, very low birth weight

VLBW premature infants have a distressingly high incidence of the chronic lung disease BPD. BPD is considered to be a multifactorial process, with hyperoxic ventilation being one of the clearly established causative factors $(1-3)$.

Over the past 20 years, much has been learned about the

Received May 10, 1990; accepted October 16, 1990.

Correspondence: Lee Frank, M.D.. Ph.D., Pulmonary Research (R-120), University of Miami School of Medicine, P.O. Box 016960, Miami, FL 33101.

Supported by NIH Grant (NHLBI) HL26029 and March of Dimes Grant 11131 . mechanism of $\mathrm{O}_{2}$ toxicity and the mechanisms cells have available for protection from levels of $\mathrm{O}_{2}$ much higher than those they are used to encountering. Among the principal cellular defenses are the antioxidant enzymes: SOD, CAT, GP, and G6-PD. Augmented AOE activity levels have been consistently associated with protection from hyperoxic exposure, and conversely, the failure to increase protective $A O E$ activities during high $\mathrm{O}_{2}$ challenge results in increased susceptibility to severe $\mathrm{O}_{2}$ induced lung damage (and lethality) (4-6).

Recent work from our laboratories has characterized the developmental ontogeny of the $\mathrm{AOE}$ defense system in the lategestation fetal lung. In the four common laboratory species examined (rat, rabbit, guinea pig, and hamster), it was found that the AOE activities are quite low until the final $15-20 \%$ of gestation. Then, during this final portion of gestation, very marked increases occur in all the antioxidant enzymes, so that the antioxidant enzyme protective capacity increases by around $500 \%$ during this prebirth period $(7,8)$. A recent report in fetal lambs suggests a similar normal late-gestational AOE activity rise (9). This very marked normal rise in the protective AOE system in the late-gestational fetal lung would imply that the very prematurely born would not only miss out on normal surfactant system development, but would also demonstrate incomplete maturation of their AOE defenses as well. Although this might suggest that the prematurely born would be prone to develop rapid-onset $\mathrm{O}_{2}$ toxicity, and might help explain why in human infants it is the more prematurely born who are most prone to develop hyperoxic lung damage and progression to BPD $(10,11)$, there is an important caveat to consider.

From the results of a large number of experimental $\mathrm{O}_{2}$ toxicity studies has evolved the concept that baseline AOE levels are of much less importance in determining resistance/susceptibility to $\mathrm{O}_{2}$-induced lung damage than are the responses of the $\mathrm{AOE}$ to hyperoxic challenge $(4,12-14)$. Thus, the premature, born with lower baseline AOE protective capacity than the full-term, might still have the capacity to augment their lung AOE activities when challenged with hyperoxia, and subsequently not be as susceptible to pulmonary $\mathrm{O}_{2}$ toxicity as their lower baseline levels might infer. But can the premature animal really respond to hyperoxia in a biochemically protective manner by increasing pulmonary AOE activity levels?

To answer this experimental question, which to date has not been previously explored, we have performed studies in which term-newborn and preterm rabbits were simultaneously exposed to hyperoxia. Comparative $\mathrm{AOE}$ responses to $\mathrm{O}_{2}$ challenge were determined, as were comparative assessments of $\mathrm{O}_{2}$-induced lung damage. The data below indicate an inability to increase $A O E$ in response to hyperoxia in the prematurely born rabbit, with a concomitant increase in hyperoxic lung damage compared with the rabbit born at term. 


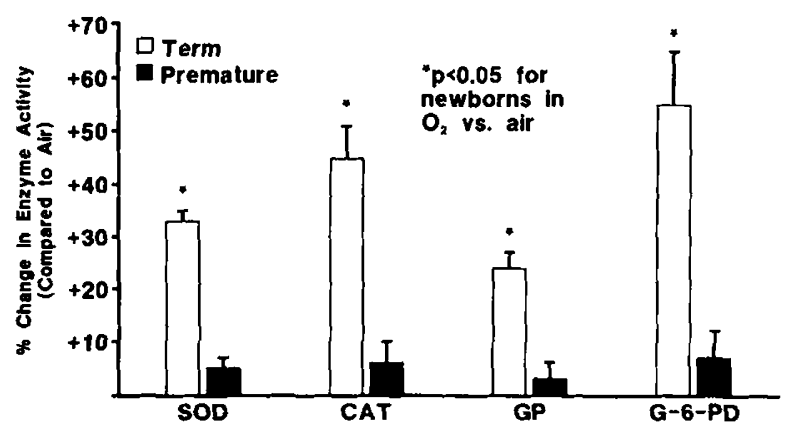

Fig. 1. Comparative AOE responses of full-term (open block) $v s$ prematurely born (solid block) rabbits to hyperoxia $\left(>90 \% \mathrm{O}_{2}, 48 \mathrm{~h}\right.$ ). Enzyme activities were calculated as activity units per mg DNA and are expressed here as \% change in $\mathrm{O}_{2}$-exposed compared with air-exposed lung enzyme values. Unlike the newborn animals, the premature animals show essentially no SOD, CAT, GP, nor G-6-PD AOE response to hyperoxia. $\left({ }^{*} p<0.05\right.$ or less for term hyperoxic values $v s$ air controls; in addition to what is described in the figure, hyperoxic values for $\mathrm{O}_{2-}$ exposed terms $v s$. prematures are significant also at $p<0.05$ or less; $n=$ 10-12 group; mean \pm I SD.)

\section{MATERIALS AND METHODS}

Animals. Timed-pregnant New Zealand albino rabbits were obtained from a reliable local supplier (K-W Farms, Tice, FL) and were housed singly in the approved veterinarian-managed University of Miami Animal Care Facility. Pregnant rabbits were either provided with breeder boxes and allowed to deliver normally (d 32 of gestation), or were killed on gestational d 29. For our premature group, we selected $29 \mathrm{~d}$ of a 32-d gestation period because at this gestational age the animals are premature enough to satisfy the definition of prematurity, yet mature enough that the majority of them are able to survive without the need for vigorous supportive care including oxygen and mechanical ventilation. Pregnant rabbits on d 29 of gestation were anesthetized with ketamine/xylazine anesthesia (ketamine, $90 \mathrm{mg} /$ $\mathrm{kg}$ :xylazine, $10 \mathrm{mg} / \mathrm{kg}$ ) by ear vein and when no pain reflex was obtained, a rapid hysterotomy was performed, the premature rabbits removed, and then the abdominal vessels in the dam were cut to kill the animal. The newly delivered 29-d gestation rabbits were rapidly resuscitated by removing the surrounding membranes, drying them vigorously, warming them on heating pads, and in some cases applying low flow $\mathrm{O}_{2}$ for 5-10 min. Initial survival was consistently $>90 \%$. All the procedures above had been given previous approval by the University of Miami Committee on Research Animal Welfare.

After preliminary tests of artificial feeding preparations, we devised a satisfactory formula for once daily gavage feeding that was not accompanied by diarrhea, bloating, or marked weight loss. The 29-d and full-term rabbits were fed each morning by gavage via a 5 French tube with a fresh diet consisting of a combination of casein hydrolysate $(3 \%)$, whey protein $(4.5 \%)$, corn oil $(3 \%)$, coconut oil $(3 \%)$, lactose $(1 \%)$, complete vitamin and mineral mix (1\%), and $\mathrm{H}_{2} \mathrm{O}$ to $100 \mathrm{~mL}$, providing approximately $100 \mathrm{kcal} / 100 \mathrm{~mL}$. The volume administered was $6 \mathrm{~mL} /$ $100 \mathrm{~g}$ body weight for the first feeding, $8 \mathrm{~mL} / 100 \mathrm{~g}$ after $24 \mathrm{~h}$, and $10 \mathrm{~mL} / 100 \mathrm{~g}$ after $48 \mathrm{~h}$. This diet allowed for body weight stability, but no weight gain during the course of the experiments [in nature, newborn rabbits are fed only once daily and do not gain body weight until after the 3rd postnatal d (15)]. (Purified diet components were from U.S. Biochemicals, Cleveland, $\mathrm{OH}$ and ICN, Costa Mesa, CA, plus Mazola Corn Oil.)

$\mathrm{O}_{2}$ exposures. After weighing and numbering the 29-d premature rabbits and the full-term pups (obtained at 12-24 h after birth), they were randomly divided and then exposed simultaneously to either $>90 \% \mathrm{O}_{2}$ or room air in matching exposure chambers controlled for temperature $\left(35^{\circ} \mathrm{C}\right)$ and humidity $(60$ $70 \%$ ). The 3.5 foot $^{3}$ clear plastic exposure chambers were monitored frequently for gas concentration with SensorMedics (Dayton, $\mathrm{OH}) \mathrm{O}_{2}$ and $\mathrm{CO}_{2}$ monitors. Exposures to $\mathrm{O}_{2}$ were continuous for 48 or $72 \mathrm{~h}$ except for a 15 -min period in the morning for feeding and cage maintenance.

Biochemical analyses. After 48 or $72 \mathrm{~h}$ in hyperoxia or room air, the full-term and premature rabbits were killed by an intraperitoneal overdose of pentobarbital. The abdominal vessels were cut to exsanguinate the animals and the lungs were perfused via the pulmonary artery (with the left atrium snipped off to promote drainage) with cold saline until white. The lungs were then weighed and homogenized in cold saline (1:15, wt/vol) (Brinkmann Polytron, Westbury, NY) for subsequent biochemical analyses. These preparatory methods and biochemical assays have been previously described in detail $(6,8,13,14)$. Lung activities of total SOD (16), CAT (17), GP (18), and G-6-PD (19) were assayed by standard spectrophotometric techniques. The lung homogenates were also assayed for total DNA (20) and protein (21) content. Purified standards for SOD, CAT, G-6-PD, DNA, and protein were from Sigma Chemical Co. (St. Louis, $\mathrm{MO}$ ); GP was from Boehringer-Mannheim (Indianapolis, IN).

Aliquots of the homogenates were subjected to lipid extraction using the method of Bligh and Dyer (22). The extract was dried under nitrogen, reconstituted with chloroform:methanol $(2: 1)$, and assayed for total lipid phosphorus following the method of Morrison (23). A portion of the dried lipid extract was used to isolate DSPC using the osmium tetroxide method described by Mason et al. (24) and then assayed for inorganic phosphorus as described above (23). A known quantity of ${ }^{14} \mathrm{C}$-dipalmitoylphosphatidylcholine (New England Nuclear, North Billerica, MA) was added before lipid extraction to estimate and correct for sequential losses. DSPC was expressed as $\mathrm{mg} / \mathrm{g}$ of wet lung weight.

In addition, a random group of air-exposed lungs (right-upper lobe) from 29-d (hysterotomy-delivered) rabbits and full-term (vaginally delivered) rabbits were subjected to wet lung weight/ dry lung weight ratio measurements (to roughly assess the effect of mode of delivery, as well as gestational age, on lung water content).

$\mathrm{O}_{2}$ toxicity parameters. For determination of $\mathrm{O}_{2}$ toxicity parameters, 29-d and term rabbit lungs (from separate 48-h air control and $\mathrm{O}_{2}$-exposed experiments) were lavaged with cold saline immediately after sacrifice (intraperitoneal pentobarbital) via a tracheal cannula. Three washes of a volume of saline sufficient to fully inflate the right lung were used for the collection of lavage protein, which was subsequently assayed by standard procedures above (21). After lavage and drainage, the right lungs

Table 1. Comparative AOE responses to 72 h of hyperoxic exposure*

\begin{tabular}{cccccc}
\hline Group & $n$ & \multicolumn{1}{c}{ SOD } & \multicolumn{1}{c}{ CAT } & \multicolumn{1}{c}{ GP } & G-6-PD \\
\hline Premature rabbits-air & $(20)$ & $12.8 \pm 1.4$ & $241 \pm 15$ & $1.34 \pm .14$ & $0.218 \pm 0.32$ \\
Premature rabbits-O $\mathrm{O}_{2}$ & $(24)$ & $13.1 \pm 1.5$ & $251 \pm 20$ & $1.38 \pm .17$ & $0.229 \pm .016$ \\
& & $(+2 \%)$ & $(+4 \%)$ & $(+3 \%)$ & $(+5 \%)$ \\
Newborns-air & $(15)$ & $20.3 \pm 1.9$ & $307 \pm 10$ & $1.56 \pm 0.24$ & $0.353 \pm .066$ \\
Newborns-O & $(17)$ & $25.0 \pm 2.1 \dagger$ & $436 \pm 42 \dagger$ & $1.92 \pm 0.20 \dagger$ & $0.462 \pm .042 \dagger$ \\
& & $(+24 \%)$ & $(+42 \%)$ & $(+31 \%)$ & $(+31 \%)$ \\
\hline
\end{tabular}

* Values are means $\pm 1 \mathrm{SD}$ for $(n)$ samples per group; enzyme activity calculated as activity units/mg DNA.

$\dagger p<0.05$ for newborns in $\mathrm{O}_{2}$ vs air. 


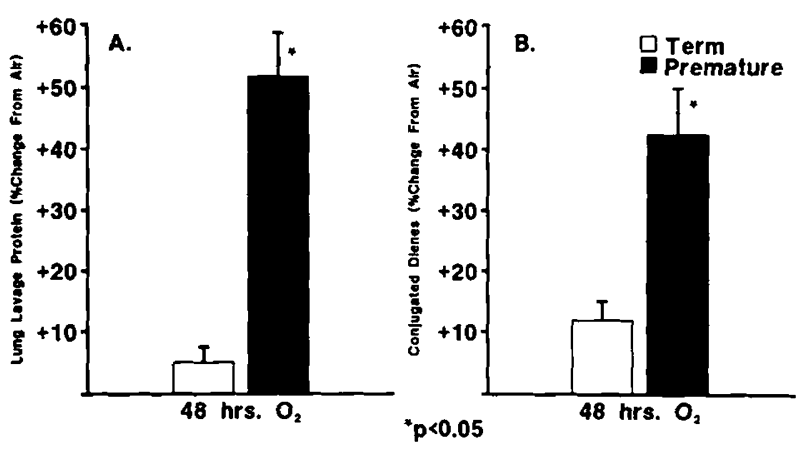

Fig. 2. Percent changes in lung lavage protein and lung conjugated dienes after $48 \mathrm{~h}$ in hyperoxia. $A$, lavage protein at $48 \mathrm{~h}$ in $>90 \% \mathrm{O}_{2}$ is markedly elevated in the preterm rabbits (solid blocks) $(0.629 \pm 0.138$ $\mu \mathrm{g} / \mathrm{mL})$ compared with their respective air mean $(0.449 \pm 0.080)$ and compared with term rabbits (air mean $0.302 \pm 0.091$; oxygen mean $0.365 \pm 0.108$ ). Full-term animals demonstrate no significant elevation between $\mathrm{O}_{2}$-exposed and air groups. $B$, lung concentration of conjugated dienes is also significantly elevated in the premature (solid block) $\mathrm{O}_{2^{-}}$ exposed compared with premature air-exposed rabbits after $48 \mathrm{~h}$ in high $\mathrm{O}_{2}$ and compared with term rabbits. The elevation in lung-conjugated diene concentration in full-term rabbits (open blocks) after $48 \mathrm{~h}$ of hyperoxia is not significant. $\left({ }^{*} p<0.05\right.$ or less between $\mathrm{O}_{2}$-exposed premature rabbits $v S$ air-exposed premature values and between $\mathrm{O}_{2-}$ exposed premature $v s$ term rabbits; $n=6-8$; mean \pm I SD.).

were subsequently perfused, weighed, and homogenized in preparation for assay of conjugated diene content. Lipids were extracted using 2:1 chloroform:methanol; the samples were then dried under nitrogen, heptane was added, and absorbance read at $233 \mathrm{~nm}$ under UV light (after blanking with heptane) (25). All comparisons were performed between $\mathrm{O}_{2}$-exposed and air-exposed lungs from both age groups.

Finally, the left lungs, which had been clamped off during the above lavage procedure, were unclamped and fixed via the tracheal cannula at a constant pressure of $20 \mathrm{~cm} \mathrm{H}_{2} \mathrm{O}$ (fixative $=10 \%$ formalin), and processed for hematoxylin and eosin light microscopic examination. The coded slides were examined for pathologic changes of atelectasis, hemorrhage, and proteinaceous pulmonary edema, and were then scored for pathologic changes independently and in a blinded fashion by the two authors, assigning either a score of 0 (clear; no pathology seen), 1 (mild; mild perivascular edema), 2 (moderate; severe perivascular edema), or 3 (severe; alveolar edema and/or hemorrhage) to each slide.

Statistical analysis. For most comparisons, analysis of variance was used for comparing the four animal groups. This was followed by Duncan's multiple range test with a $p<0.05$ value used to indicate significant differences between the test groups (26).

\section{RESULTS}

The newborn and preterm rabbits tolerated the feedings well after a satisfactory diet mix had been devised. In room air, $>90 \%$ of the full-term and $\sim 80 \%$ of the premature animals survived the $3 \mathrm{~d}$ of artificial nourishment by gavage feeding, and body weights were stabilized during this period after an initial small weight loss at $24 \mathrm{~h}$.

Biochemical results. Simultaneous experiments in full-term and prematurely born rabbits for antioxidant enzyme analysis were done after $48 \mathrm{~h}$ of hyperoxic or room air exposure (four experiments, $n=10-12$ rabbits/exposure group/gestational age) and after $72 \mathrm{~h}$ of high $\mathrm{O}_{2}$ or room air exposure (four experiments, $n=15-17$ term rabbits/exposure group and 20-24 29-d rabbits/ exposure group). Figure 1 illustrates the comparative biochemical responses to $48 \mathrm{~h}$ of high $\mathrm{O}_{2}$ challenge in the two age groups. It is apparent that unlike the full-term rabbits, who are able to mount significant $33 \%-55 \%$ increases in antioxidant enzyme activity levels after $48 \mathrm{~h}$ of hyperoxia, the premature rabbits manifest essentially no antioxidant enzyme response to hyperoxia (7\% or less). Table 1 shows the comparative enzyme responses when exposure to $>90 \% \mathrm{O}_{2}$ was prolonged to $72 \mathrm{~h}$, and again shows a failure of the prematurely born rabbit lung to mount an appropriate protective antioxidant enzyme response to high $\mathrm{O}_{2}(5 \%$ or less increase in premature rabbits after $72 \mathrm{~h}$ of $>90 \% \mathrm{O}_{2}$ exposure, compared with the significant increases in the term hyperoxia-exposed rabbits).
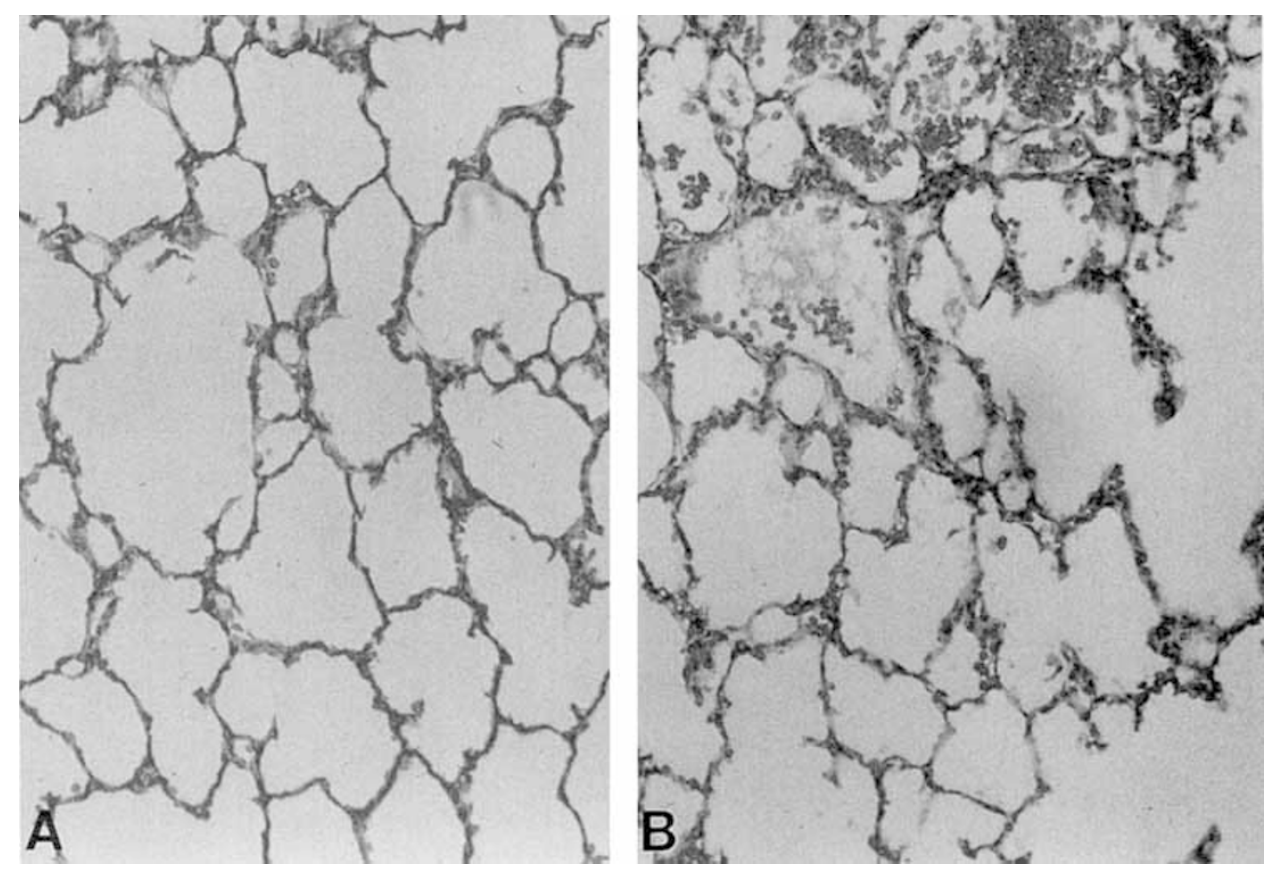

Fig. 3. Photomicrograph $A$ : light micrograph (70X) of full-term rabbit lung after $48 \mathrm{~h}$ of $>90 \% \mathrm{O}_{2}$. No evidence of perivascular edema or intraalveolar edema or hemorrhage is present. $B$, light micrograph (70X) of $29-\mathrm{d}$ premature rabbit lung after $48 \mathrm{~h}$ of $>90 \% \mathrm{O}_{2}$ exposure. Clearly seen in this section is evidence of intraalveolar hemorrhage and edema. 
Table 2. Comparative microscopic lung pathology in premature and full-term rabbits exposed to $>90 \% \mathrm{O}_{2}$ for $48 \mathrm{~h}^{*}$

\begin{tabular}{lcl}
\hline & Pathology score & Individual values \\
\hline Full-term $(n=5)$ & $0.7 \pm 0.4$ & $(1,0,1,1,0.5)$ \\
Premature $(n=5)$ & $2.2 \pm 0.8 \dagger$ & $(2,3,1,3,2)$ \\
\hline
\end{tabular}

* Mean \pm 1 SD. Scoring (blinded) based on $0=$ normal, $1=$ mild perivascular edema, 2 = severe perivascular edema, $3=$ alveolar edema and/or hemorrhage.

$\dagger p<0.05$ between groups.

The mean DSPC values showed little change with hyperoxic exposure in either age group studied [newborn $48 \mathrm{~h}$, air mean $6.69 \pm 1.26$ versus oxygen mean $5.94 \pm 1.39 \mathrm{mg} / \mathrm{g}$ lung $(-6 \%)$ premature $48 \mathrm{~h}$, air mean $4.80 \pm 0.91$ versus oxygen mean 4.32 $\pm 0.82(-12 \%)$; newborn $72 \mathrm{~h}$, air mean $8.42 \pm 0.80$ versus oxygen mean $7.89 \pm 0.90(-6 \%)$; premature $72 \mathrm{~h}$, air mean 5.07 \pm 0.48 versus oxygen mean $4.92 \pm 0.24(-3 \%)]$.

Measurements of wet lung weight/dry lung weight ratios from randomly selected right upper lobes of preterm (hysterotomy delivery) and term (vaginal delivery) animals after $48 \mathrm{~h}$ of air exposure were not different between the two groups (i.e. $4.98 \pm$ 0.28 for term rabbits versus $5.01 \pm 0.15$ for preterm rabbits, $n=$ 5 per group), thus suggesting that differences in lung water content are not likely to be responsible for differences in antioxidant enzyme response or oxygen tolerance between the two age groups studied.

Indices of $\mathrm{O}_{2}$ toxicity. Few rabbits of either group died during the 48 or $72 \mathrm{~h}$ of $\mathrm{O}_{2}$ exposure. Figure 2 shows the comparative lung lavage protein data (a reflection of pulmonary edema) and the lung conjugated diene data (a reflection of $\mathrm{O}_{2}$-induced lipid peroxidation) after $48 \mathrm{~h}$ of hyperoxic exposure. The $29-\mathrm{d}$ premature rabbits demonstrated significant elevations in lung lavage protein $(>50 \%)$ and lung tissue conjugated dienes $(>40 \%)$ compared with values in air-exposed preterm rabbits; full-term rabbits did not manifest significant increases between hyperoxia and airexposed animals in either measurement of lung damage. Based on these parameters, $\mathrm{O}_{2}$ toxicity was significantly more pronounced during equivalent exposure periods in the premature versus the full-term animals.

Figure 3 (photos $A$ and $B$ ) are taken from representative lung fields from 29-d premature and term rabbits after $48 \mathrm{~h}$ of $>90 \%$ $\mathrm{O}_{2}$ exposure. The lung of the term $\mathrm{O}_{2}$-exposed rabbit appears relatively well inflated, with airways clear of proteinaceous edema and hemorrhage; the premature $\mathrm{O}_{2}$-exposed rabbit lung demonstrates areas of intraalveolar hemorrhage and proteinaceous edema. Table 2 gives a quantitative summary of these comparative lung micropathologic changes. Using a scoring system ranging from 0 (clear) to 3 (severe), preterm lungs after $48 \mathrm{~h}$ of hyperoxia had a significantly more severe mean micropathologic score $(2.2 \pm 0.8)$ compared with term rabbits exposed to hyperoxia for the same time interval $(0.7 \pm 0.4), p<0.05$.

\section{DISCUSSION}

Work from our own and other laboratories $(7-9,27,28)$ has strongly suggested that due to the late gestational maturation of the lung AOE system the prematurely born will have very low baseline antioxidant enzyme activity levels. These low baseline activity levels (combined with low levels of other antioxidants such as vitamin $E$, vitamin $A$, ascorbate, ceruloplasmin, etc.) of the prematurely born may provide a partial biochemical explanation for why VLBW premature infants are prone to develop hyperoxia-related chronic lung damage. However, evidence from a large number of experimental studies clearly indicates that baseline activity of the antioxidant enzyme defense system is not the best predictor of tolerance or susceptibility to $\mathrm{O}_{2}$-induced lung damage (and lethality). Instead, the ability to respond to hyperoxic exposure with an increase in pulmonary antioxidant enzymes correlates most closely with hyperoxic tolerance and survival. For example, adult rats exposed to $>95 \% \mathrm{O}_{2}$ will nearly all die within $60-72 \mathrm{~h}$; these non- $\mathrm{O}_{2}$ tolerant adult rats demonstrate no increase in their pulmonary AOE activity levels during exposure to hyperoxia (14). However, effective protection from $>95 \% \mathrm{O}_{2}$ and markedly improved survival can be produced in adult rats by a number of experimental manipulations-preexposure to sublethal concentrations of hyperoxia, preexposure to hypoxia, and treatment with low doses of bacterial endotoxinall of which are subsequently associated with increased pulmonary SOD, CAT, and GP in the adult rat and resultant prolonged survival in hyperoxia (29-31). Similar results have been obtained in neonatal animal versus adult animal species studies $(13,14)$. In these studies, the neonatal animals demonstrate prolonged survival in hyperoxia in association with the ability to rapidly mount a protective $\mathrm{AOE}$ response to hyperoxic exposure, whereas the parent adult animals manifest neither the ability to survive for more than $3-5 \mathrm{~d}$ in hyperoxia nor the ability to increase AOE during high $\mathrm{O}_{2}$ exposure. It is interesting to note the presence of species specificity in respect to the hyperoxic endotoxin response described above; unlike rats, 3- to 11-d-old lambs, although demonstrating improved survival and clinical status in high $\mathrm{O}_{2}$ after endotoxin infusion, did not manifest elevations in lung AOE levels (32).

Our hypothesis in the present study was that prematurely born animals, unlike full-term animals, would show a failure to mount a protective increase in pulmonary AOE levels during high $\mathrm{O}_{2}$ exposure and, lacking the capacity for this protective enzyme response, the prematurely born would show increased susceptibility to $\mathrm{O}_{2}$-induced lung damage. The data strongly support this hypothesis as we consistently observed a failure of AOE responsiveness to hyperoxia in our prematurely born animals and an "appropriate" lung biochemical response to high $\mathrm{O}_{2}$ in the fullterm animals. Consistent with the dichotomous AOE responses to hyperoxia were the comparative indications of $\mathrm{O}_{2}$-induced lung damage. Equivalent $\mathrm{O}_{2}$ exposure periods produced a variety of evidence for increased pulmonary $\mathrm{O}_{2}$ toxicity in the premature animals versus the full-term rabbits (i.e. lavage protein, pulmonary micropathology). Conjugated diene measurements, known to have methodologic shortcomings [including the fact that their quantitation cannot be used as an absolute measure of in vivo lipid peroxidation (33)], nonetheless provided an additional comparative means of assessing hyperoxic-related lung damage between term and preterm animals, and yielded results highly consistent with the lavage protein and pulmonary micropathology determinations.

To our knowledge, this is the first report of the inability of the prematurely born (versus the full-term newborn) to respond with an appropriate biochemical response to hyperoxic challenge. The applicability of these results to the VLBW infant would be strengthened with confirmatory studies in other species (e.g. sheep, primate). Furthermore, definitive confirmation of these results would necessitate the same mode of delivery (i.e. hysterotomy) for both preterm and term animals. This would totally rule out the possibility that the lack of inducibility of the AOE in the preterm animal might be related to the fact that the AOE system was not exposed to the stimulatory hormonal and prostaglandin changes associated with spontaneous labor and vaginal delivery. Nonetheless, if extrapolatable to the human premature infant, the present findings would provide additional support for the observed susceptibility of these small infants to hyperoxic lung injury and the progressive development of BPD. Not only may the baseline levels of the pulmonary antioxidant defensive enzymes be low in the very prematurely born infant, but the infants' immature lungs may also be unable to augment their AOE complement when exposed to hyperoxic therapeutic treatment.

Finally, the findings of this study would seem to lend themselves to future studies involving exploration of this lack of responsiveness of the premature AOE system on the molecular level and to experimental pharmacologic/hormonal interven- 
tions to possibly stimulate the unresponsive lung of the prematurely born to manifest an appropriate AOE defensive response to hyperoxic exposure. This might improve the ability of the premature to resist $\mathrm{O}_{2}$-induced lung injury and its chronic sequelae.

\section{REFERENCES}

1. O'Brodovich HM, Mellins RB 1985 Bronchopulmonary dysplasia: unresolved neonatal acute lung injury. Am Rev Respir Dis 132:694-709

2. Bancalari E 1988 Pathogenesis of bronchopulmonary dysplasia: an overview. In: Bancalari E, Stocker JT (eds) Bronchopulmonary Dysplasia. Hemisphere Washington, DC, pp 3-15

3. Bonikos DS, Bensch KF 1988 Pathogenesis of bronchopulmonary dysplasia In: Merritt TA, Northway Jr WH, Boynton BR (eds) Bronchopulmonary Dysplasia. Blackwell Scientific, Boston, pp 33-58

4. Huber GL, Drath DB 1981 Pulmonary oxygen toxicity. In: Gilbert DL (ed) Oxygen and Living Processes. An Interdisciplinary Approach. Springer Verlag, New York, pp 273-342

5. Freeman BA, Crapo JD 1982 Biology of disease. Free radicals and tissue injury. Lab Invest 47:412-426

6. Frank L, Summerville J, Massaro D 1980 Protection from oxygen toxicity: role of the endogenous antioxidant enzymes of the lung. $\mathrm{J}$ Clin Invest 65:1104-1110

7. Frank L, Sosenko IRS 1987 Development of lung antioxidant enzyme system in late gestation: possible implications for the prematurely-born infant. $\mathbf{J}$ Pediatr 110:9-14

8. Frank L, Sosenko IRS 1987 Prenatal development of lung antioxidant enzymes in four species. J Pediatr 110:106-110

9. Walther FJ, Wade AB, Warburton D 1991 Ontogeny of antioxidant enzymes in the fetal lamb lung. Exp Lung Res (in press)

10. Escobedo MB, Gonzalez A 1986 Bronchopulmonary dysplasia in the tiny infant. In: Vidyasayar B (ed) The Tiny Baby, Clinics in Perinatology, Vol 13. WB Saunders, Philadelphia, pp 315-326

11. Boynton BR 1988 The epidemiology of bronchopulmonary dysplasia. In Merritt TA, Northway Jr WH, Boynton BR (eds) Bronchopulmonary Dysplasia. Blackwell Scientific, Boston, pp 19-32

12. Roberts RJ, Frank L 1984 Developmental consequences of oxygen toxicity. In: Kacew S, Reasor M (eds) Toxicology and the Newborn. Elsevier Scientific New York, pp 141-171

13. Frank L, Bucher JR, Roberts RJ 1978 Oxygen toxicity in neonatal and adult animals of various species. J Appl Physiol 45:699-704

14. Yam J, Frank L, Roberts RJ 1978 Oxygen toxicity: comparison of lung biochemical responses in neonatal and adult rats. Pediatr Res 12:115-119
15. Aprille JR, Rulfs J 1976 A convenient neonatal method for developmental studies requiring artificial diets. Biol Neonate 30:109-115

6. McCord JM, Fridovich I 1969 Superoxide dismutase: an enzymic function of erythrocuprein (hemocuprein). J Biol Chem 244:6049-6055

17. Holmes RS, Masters CJ 1970 Epigenetic interconversion of the multiple forms of mouse liver catalase. FEBS Lett 1 1:45-48

18. Paglia DE, Valentine WN 1967 Studies on the quantitative and qualitative characteristics of erythrocyte glutathione peroxidase. J Lab Clin Med 70:158 169

19. Langdon RG 1966 Glucose-6-phosphate dehydrogenase from erythrocytes. In: Colowick SP, Kaplan NP (eds) Methods in Enzymology. Academic, New York, pp 126-131

20. Richards GM 1974 Modifications of the diphenylamine reaction giving increased sensitivity and simplicity in the estimation of DNA. Anal Biochem 57:369-376

21. Schacterle RE, Pollack RL 1973 A simplified method for the quantitative assay of small amounts of protein in biological material. Anal Biochem 51:654 655

22. Bligh EF, Dyer WJ 1959 A rapid method of total lipid extraction and purification. Can J Biochem Physiol 37:911-917

23. Morrison WR 1964 A fast, simple and reliable method for the microdetermination of phosphorus in biological materials. Anal Biochem 11:218-224

24. Mason RJ, Nellenbogen J, Clements JA 1976 Isolation of disaturated phosphatidylcholine with osmium tetroxide. J Lipid Res 17:281-284

25. Ward PW, Till GO, Hatherill JR, Annesley TM, Kunkel RG 1985 Systemic complement activation, lung injury, and products of lipid peroxidation. $J$ Clin Invest 76:517-527

26. Steel RGD, Torrie JH 1960 Principles and Procedures of Statistics. McGrawHill, New York, pp 67-98, 366-387

27. Gerdin E, Tyden O, Eriksson UJ 1985 The development of antioxidan enzymatic defense in the perinatal rat lung: activities of superoxide dismutase glutathione perioxidase, and catalase. Pediatr Res 19:687-691

28. Tanswell AK, Freeman BA 1984 Pulmonary antioxidant enzyme maturation in the fetal and neonatal rat. I. Developmental profiles. Pediatr Res 18:584587

29. Kimball RE, Reddy K, Pierce TH, Schwartz LW, Mustafa MC, Cross CE 1976 Oxygen toxicity: augmentation of antioxidant defense mechanisms in rat lung. Am J Physiol 230:1425-1431

30. Frank L, Yam J, Roberts RJ 1978 The role of endotoxin in protection of adult rats from high oxygen lung toxicity. J Clin Invest 61:269-275

31. Frank L 1982 Protection from pulmonary oxygen toxicity by pre-exposure of rats to hypoxia: role of the antioxidant enzyme system. J Appl Physiol $53: 475-482$

32. Hazinski TA, Kennedy KA. France ML, Hansen TN 1988 Pulmonary $\mathrm{O}_{2}$ toxicity in lambs: physiological and biochemical effects of endotoxin infusion. J Appl Physiol 65:1579-1585

33. Smith CV, Anderson RE 1987 Methods for determination of lipid peroxidation in biological samples. Free Rad Biol Med 3:341-344 